Article

\title{
Experimental Investigation on Effect of Wall Roughness and Lubricant Film on the Adhered Fuel Film of N-Butanol-Diesel Blends after Spray Impingement
}

\author{
Xingyu Liang ${ }^{1, *}$, Hongsheng Zhang ${ }^{1}$, Gequn Shu ${ }^{1}$, Yuesen Wang ${ }^{1}{ }^{10}$, Xiuxiu Sun ${ }^{1}$, \\ Hanzhengnan $\mathrm{Yu}^{2}$ and Ming $\mathrm{Ge}^{1}$ \\ 1 State Key Laboratory of Engines, Tianjin University, Tianjin 300072, China; z736312256@tju.edu.cn (H.Z.); \\ sgq@tju.edu.cn (G.S.); wys@tju.edu.cn (Y.W.); xiuxiu6536@126.com (X.S.); geming@tju.edu.cn (M.G.) \\ 2 China Automotive Technology \& Research Center, Tianjin 300300, China; yhzntju@163.com \\ * Correspondence: lxy@tju.edu.cn; Tel.: +86-22-2789-1285
}

Received: 20 May 2018; Accepted: 12 June 2018; Published: 15 June 2018

\begin{abstract}
The effect of wall roughness with different lubricant film thicknesses on the characteristics of adhered fuel films of diesel-n-butanol blending fuels after spray impingement has been investigated. Four steel plates with different types of roughness (root mean square height-Sq) that were coated with different lubricant film thicknesses $\left(h_{1}\right)$ were used as impinged walls. The experimental conditions included dry walls $\left(h_{1}=0\right)$, semi-wetted walls (SWW) with different thin oil films $\left(0<\mathrm{h}_{1} / \mathrm{Sq}<1\right)$, and fully wetted walls (FWW) with a thick lubricant film $\left(\mathrm{h}_{1}>\mathrm{Sq}\right)$. The results indicate that the adhered fuel mass ratio ( $)$ ) of blended fuel with $25 \%$ n-butanol (B25) was higher than that of blended fuel with 15\% n-butanol (B15) under the same conditions. $\varepsilon$ increased with an increase in Sq on the dry walls, but, under SWW conditions, it decreased with an increase in oil film thickness. The fuel film morphology was almost unaffected by the change in Sq, but the results implied that the roughness parameter-Skewness (Ssk) exerted a greater impact. The mean thickness $h_{a}$ and accumulated diameter $D_{1}$ of the adhered fuel film increased with an increase in $h_{1}$, but, under FWW conditions, the effect of the roughness on the adhered film's features was insignificant.
\end{abstract}

Keywords: wall roughness; lubricant film; n-butanol-diesel blends; spray impingement; adhered fuel film

\section{Introduction}

In conventional diesel engines, a "trade-off" relationship exists between nitrogen oxide (NOx) and soot emissions [1]. To resolve this problem, advanced combustion modes have been proposed such as homogeneous charge-compression ignition (HCCI) and premixed charge-compression ignition (PCCI) [2,3]. Early injection is a key technology that can extend the mixing time of liquid fuel and air to achieve a homogeneous mixture and a high efficient combustion. However, because of the early spray time, the cylinder pressure and temperature are lower, which leads to an increase in spray penetration and a decrease in droplet evaporation. Part of the injected fuel will impact the cylinder liner or piston head. The adhered fuel film evaporates slowly and dilutes the lubricant film on the cylinder liner $[4,5]$. The mixture concentration near the wall will be too rich, which contributes to a deterioration in combustion and carbon monoxide (CO) and hydrocarbon (HC) emissions.

Therefore, the study of the fuel-injection and impingement characteristics is significant and extensive research has been conducted experimentally and numerically to reveal the mechanism of spray and impingement. Akop et al. [6,7] investigated the features of the fuel film that were adhered 
on an original dry disk after impingement with different operating parameters. The adhered fuel tended to decrease with an increase in injection pressure, ambient pressure, and disk inclination angle. In addition, the adhered film thickness showed a decreasing trend with an increase in injection pressure but a decrease in the impingement distance. Panão et al. [8] studied the influence of cross-flow on the droplet impingement process visually with phase-Doppler technology. Cross-flow would weaken the impact energy that was available for secondary atomization, but the advantage was the airflow, which enhanced the fuel film evaporation and avoided the re-impact of secondary droplets on the plate. Wang et al. [9] used an ultra-high-speed imaging technique to study the process of isooctane droplets impacting on a wall. Microscopic pictures showed that droplet splashing or rebounding was affected mainly by the high spray velocity in the early stage, but then the droplets tended to stick on the wall for lower-velocity and adhered-film conditions. Zhang et al. [10] modified the widely used Estrade et al.'s impact model [11] and proposed a simplified droplet-collision model to predict the spray and splashing behavior. The improved model could provide a reliable prediction of droplet shape, velocity, and Sauter mean diameter under different ambient pressure conditions.

Besides ambient factors and injection parameters, splashing and spreading after impingement are affected significantly by the wall conditions such as the roughness, texture, liquid film, and wall temperature [12]. Deendarlianto et al. [13] studied the influence of wall roughness on the dynamic behavior of single and multiple successive water droplets after impacting the inclined hot plate surface. The surface roughness played a significant role in the cooling process. For a hot wall that was contacted with successive water droplets, a higher roughness yielded a shorter droplet evaporation time on the plate. During the later stage of droplet contacting and plate contacting, the spreading diameter increased with an increase in wall roughness. Tang et al. [14] conducted experimental research on the impact behavior of single droplets of water, decane, ethanol, and tetradecane. The researchers were particularly interested in the effect of wall roughness. With an increase in Weber number (We) and roughness $(\mathrm{Ra})$, splashing that was caused by secondary droplets was favored. The roughness could slow down the spreading process, which decreased the dimensionless maximum spreading diameter $\beta_{\max }$. However, the transition from spreading to splashing was enhanced by the increase in Ra. Zhang et al. [15] compared the characteristics of microdroplet spray impingement on dry and wet walls. The existence of the liquid film changed the critical number $K$, which determined the boundary of the droplet splash/non-splash. The liquid film on the plate promoted microdroplet splashing. Guo et al. [16] conducted a simulation study to investigate droplet evolution after colliding with a plate covered by liquid film with the combined level set and volume of fluid (CLSVOF) method. The splashing time is advanced by accelerated droplet motion and the spreading diameter tended to decrease with an increase in liquid film thickness. The above analysis shows that most of the wall surface parametric study focused on the effect of Ra or liquid film thickness on the characteristics of a single water droplet's impingement process. Rarely have practical conditions for the spray impingement of engines been considered closely where the effects of cylinder surface roughness and lubricant film exist simultaneously. Therefore, this paper focuses mainly on the combined influence of different types of roughness with lube oil film thickness on the quality and microscopic characteristics of the adhered fuel film to analyze the spray-impingement processes under different simulated engine operation conditions. A sequence of two-dimensional measured evaluation parameters of roughness such as Sa and Sq (see Introduction, Section 2) could represent the roughness more comprehensively than the one-dimensional evaluation parameter $\mathrm{Ra}$ that is used in most previous papers.

To reduce excess $\mathrm{CO}$ and $\mathrm{HC}$ emissions that are caused by early injection except for increasing the mass of air intake [17], many oxygenated alternative fuels that can improve the combustion efficiency have been studied and their use has been attempted in diesel engines such as alcohol fuels [18,19], ester fuels [20], canola oil [21], and other biodiesel fuels [22]. Among these promising diesel substitutes, n-butanol exhibits unique advantages. For instance, it has a higher energy density and a lower evaporation pressure, which make it easy to evaporate and mix with air to achieve a greater amount of burning [23]. Moreover, it can be dissolved in diesel easily in any proportion without phase separation. 
Additionally, it results in a lower steel corrosion [24]. For future applications, much effort has been expended to investigate the characteristics of spray, combustion, and emission for use of n-butanol in diesel engines. The microscopic spray features of neat soybean biodiesel and $20 \% \mathrm{n}$-butanol biodiesel blends by using the particle/droplet image analyzing (PDIA) technology, which was determined by Mo et al. [25]. The droplet diameter at the spray periphery was larger than that in the spray center because of the air-entrainment effect at the spray periphery. Fewer droplets existed near the sprayed liquid core where the effect of viscosity was important. Research by Chen et al. [26] indicated that the production of $\mathrm{CO}, \mathrm{HC}$, and soot was lower when n-butanol was used in diesel engines compared with methanol and ethanol under the same conditions. The results of Yao [27], Şahin [28], and Yilmaz [29] indicate that the use of diesel-n-butanol blending fuels could decrease the soot and CO emissions of diesel engines significantly without deteriorating in fuel economy and NOx emissions.

These achievements indicate that diesel-n-butanol blends are a promising fuel and are worthy of in-depth study [25]. In our previous work [30-32], we have studied the effect of the injection parameters, ambient parameters, and fuel characteristics on the impingement process and adhered film distribution. However, according to the analysis above, the surface condition of the impinged wall also plays a significant role in droplets' adhesion and splashing. In this work, we originally attempted to explore the effect of surface roughness's evaluated parameters and lubricant film with different thickness on the spray-impingement process. We expected to establish methods to control the fuel-adherence phenomenon. A report by Sakda [33] indicates that the appropriate volumetric fraction of n-butanol should be close to $20 \%$, and based on Reference [32], the adhered film ratio did not changed much when the blended ratio was lower than $20 \%$. Therefore, the volumetric ratios for n-butanol in this work were $15 \%$ and $25 \%$ and were referred to as B15 and B25, respectively. The physical properties of the two blends were estimated according to the data of References $[34,35]$ and provided in Table 1. We also supplemented the properties of pure diesel for reference.

Table 1. Physical properties of the fuels $\left(20^{\circ} \mathrm{C}\right)$.

\begin{tabular}{cccc}
\hline $\begin{array}{c}\text { Fuel } \\
\text { Abbreviation }\end{array}$ & $\begin{array}{c}\text { Density } \\
\left(\mathbf{k g} / \mathbf{m}^{\mathbf{3}}\right)\end{array}$ & $\begin{array}{c}\text { Dynamic Viscosity } \\
\left(\times \mathbf{1 0}^{-\mathbf{3}} \mathbf{p a} \cdot \mathbf{s}\right)\end{array}$ & $\begin{array}{c}\text { Surface Tension } \\
(\mathbf{m N} / \mathbf{m})\end{array}$ \\
\hline B15 & 849.8 & 3.627 & 26.03 \\
B25 & 845.1 & 3.491 & 25.57 \\
Pure diesel & 856.5 & 3.847 & 26.67 \\
\hline
\end{tabular}

\section{Materials and Methods}

\subsection{Experimental Apparatus and Materials}

To investigate the characteristics of the adhered fuel film after spray impingement, the spray-impingement and film-thickness measurement system were used, which is shown in Figure 1. Figure 1a shows the constant-volume vessel with a common-rail injection system for fuel spray and wall impact including the high-pressure common rail system, the constant-volume vessel-injection system, and the electronic control unit. The injector with a single hole is mounted in the central top of the vessel and the angle between the spray direction and the plate's horizontal plane could be adjusted by rotating the plate $15^{\circ}-90^{\circ}$. Therefore, the plate surface will be impacted by the injected fuel and covered by the adhering fuel film. The blended mixture in the tank were premixed and transported to the injector by a high oil pump and the injection pressure can be controlled between $0 \mathrm{MPa}-300 \mathrm{MPa}$ by adjusting the solenoid valve opening. More details about this part of the system can be found in Reference [30]. After the injection, the plate surface with a fuel film will be measured by using the oil film sensor from Infralytic, which was illustrated in Figure 1b. This instrument is portable and uses infrared filter technology, which can determine the fuel film thickness on the metal surface accurately and rapidly. Its working principle is based on the Lambert-Beer law [36], which can calculate the liquid film thickness by using light absorbance after a light beam has passed through the film. Details of this device are described in References [31,35]. 


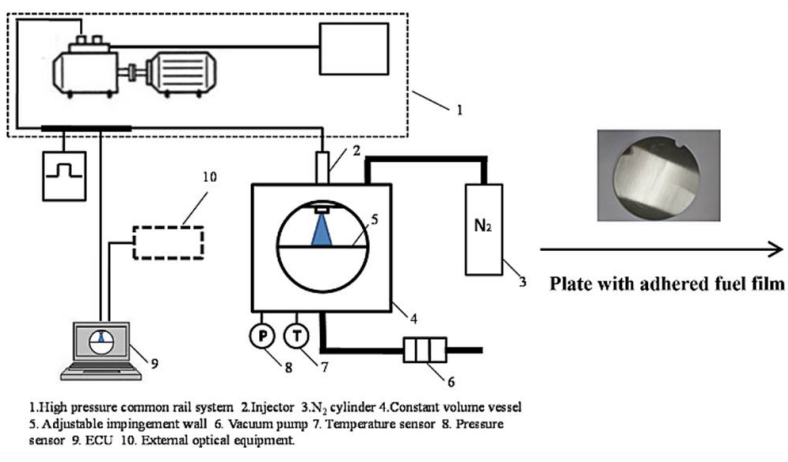

(a)

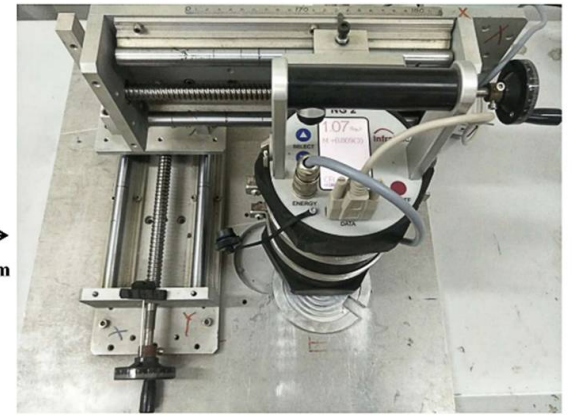

(b)

Figure 1. Spray impingement and film-thickness measurement system: (a) schematic diagram of spray-impingement test rig [30]; (b) wall film thickness measurement instrument [31].

To study the effect of wall roughness on the fuel film's characteristics, four circular cold-rolled steel plates with different surface roughness types $(\mathrm{Sq}=0.24 \mu \mathrm{m}, 1.00 \mu \mathrm{m}, 1.84 \mu \mathrm{m}, 2.59 \mu \mathrm{m})$ have been used. The plate shape is identical and their diameter and thickness are $95 \mathrm{~mm}$ and $3 \mathrm{~mm}$, respectively. One surface of each plate is ground by the grinding machine and a small area has been cut to measure the wall roughness by using a 3D optical profiler. The plates and corresponding measured area's microtopography are shown in Figure 2 with each number following $\xi$. For most previous papers analyzed above (Section 1), researchers always focused on the linear evaluation parameter of surface roughness ( $\mathrm{Ra}$ or $\mathrm{Rq}$ ), but it could only reflect the one-dimensional micro-texture height distribution. In this work, we used mainly the root mean square height Sq to analyze the influence of roughness on the fuel film. It is Rq's areal expansion with two-dimensional form and it can represent the practical roughness of the plate surface in most cases so that it will have a real impact on droplets' spreading during the impingement process. Numbers that follow $\xi$ are arranged according to the value of Sq from smallest to largest, which means that the $\xi_{1}$ plate is smoothest and $\xi_{4}$ is rougher than the others. The results of the wall roughness parameters of these plates are shown in Figure 3. Table 2 provides the formula definition where $\mathrm{z}(\mathrm{x}, \mathrm{y})$ is the height of the measured points in the $(\mathrm{x}, \mathrm{y})$ two-dimensional planes and " $\mathrm{A}$ " is the area of the measured region. Result of Figure 3 shows that Sa and Sq both have the same development trend for their averaging characteristics. The averaged performance also influences the maximum height and $\mathrm{Sz}$ has a similar changing trend with $\mathrm{Sa}$ and $\mathrm{Sq}$. The differences of Ssk among $\xi_{1}, \xi_{3}$, and $\xi_{4}$ are small, but which of $\xi_{2}$ is lower obviously than others. The relationship of the overall concave-convex extent of the wall and Ssk is that, if Ssk $<0$, the surface microstructure shows a high height distribution, so it implies that the convex extent of $\xi_{2}$ is relatively significant. Additional details on these roughness parameters are given in Reference [37].

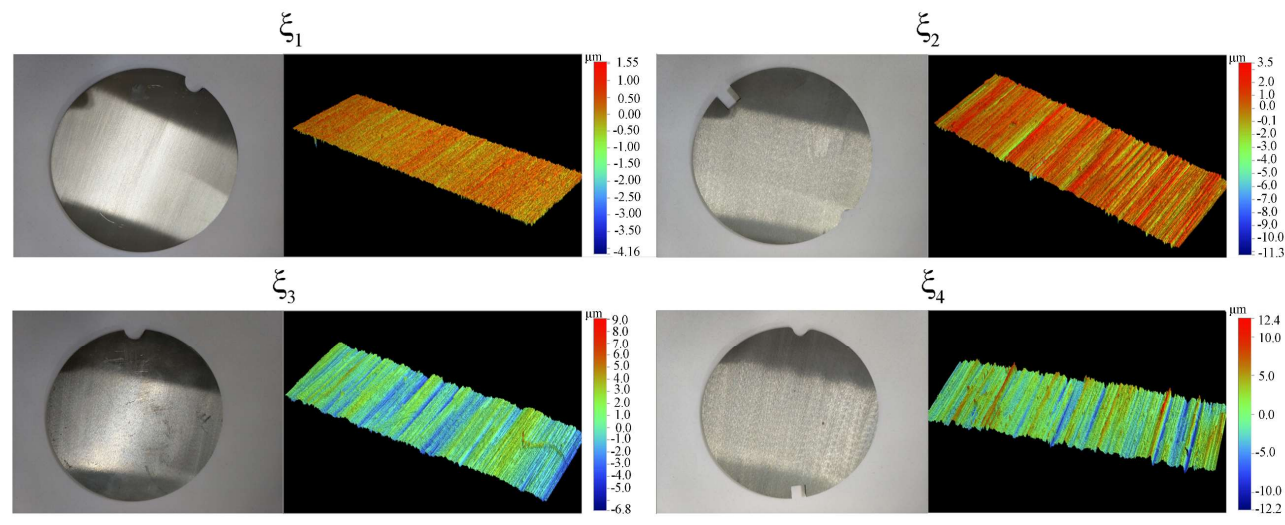

Figure 2. Impinged plates with microscopic surface images. 


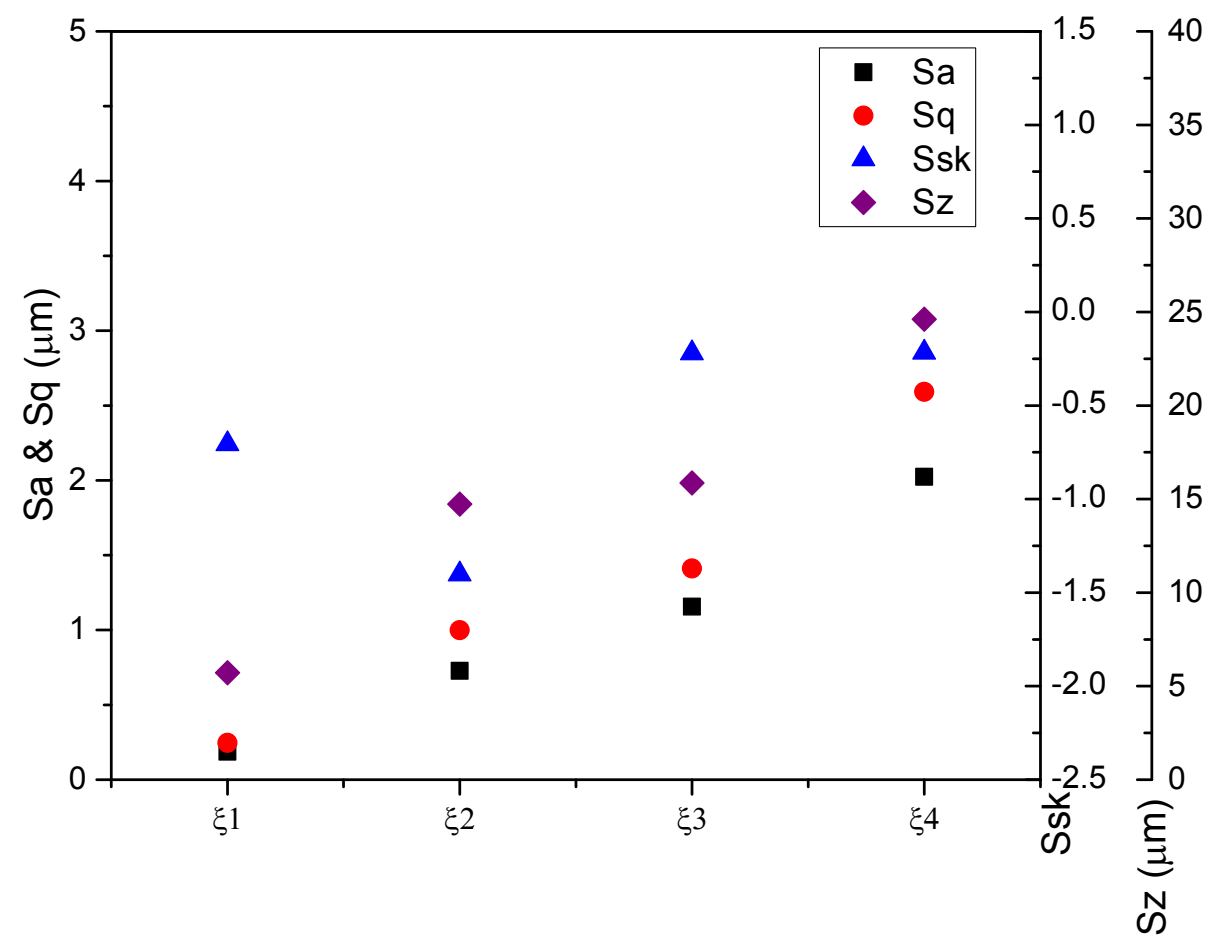

Figure 3. Results of the surface roughness parameters of test plates.

Table 2. Definition and formula of roughness parameters.

\begin{tabular}{cc}
\hline Roughness Parameter & Definition Formula \\
\hline Arithmetic mean height (Sa) & $\mathrm{Sa}=\frac{1}{\mathrm{~A}} \iint_{\mathrm{A}}|\mathrm{z}(\mathrm{x}, \mathrm{y})| \mathrm{dxdy}$ \\
\hline Root mean square height (Sq) & $\mathrm{Sq}=\sqrt{\frac{1}{\mathrm{~A}} \iint_{\mathrm{A}} \mathrm{z}^{2}(\mathrm{x}, \mathrm{y}) \mathrm{dxdy}}$ \\
\hline Skewness (Ssk) & $\mathrm{Ssk}=\frac{1}{\mathrm{Sq}^{3}}\left[\frac{1}{\mathrm{~A}} \iint_{\mathrm{A}} \mathrm{z}^{3}(\mathrm{x}, \mathrm{y}) \mathrm{dxdy}\right]$ \\
\hline Maximum height (Sz) & $\mathrm{Sz}=\max _{\mathrm{A}} \mathrm{z}(\mathrm{x}, \mathrm{y})+\left|\min _{\mathrm{A}} \mathrm{z}(\mathrm{x}, \mathrm{y})\right|$ \\
\hline
\end{tabular}

\subsection{Experimental Conditions}

Table 3 shows the operational conditions of this experiment. To minimize the evaporation of liquid film to obtain details of the film features, the injection and measurement process occurs under room pressure and temperature. The blended fuel will be sprayed by a high pressure and impinged vertically on the plate (angle between injection direction and the horizontal plane of the plate was fixed in $90^{\circ}$ ). Three wall conditions will exist including the dry wall condition that indicates the influence of wall roughness on the film characteristics and the fully wetted wall (FWW) condition means that each plate surface will be covered by an original lubricating oil film with a thickness $\left(3-4 \mathrm{~g} / \mathrm{m}^{2}, \sim 3.3-4.4 \mu \mathrm{m}\right)$ that is larger than Sq. The semi-wetted wall (SWW) condition entails that the plate will be covered by original lubricating oil with a thickness of $0 \mathrm{~g} / \mathrm{m}^{2}$ (dry wall), $1-2 \mathrm{~g} / \mathrm{m}^{2}, 2-3 \mathrm{~g} / \mathrm{m}^{2}$, and $3-4 \mathrm{~g} / \mathrm{m}^{2}$, and the wall roughness is fixed at a maximum $\mathrm{Sq}=2.59 \mu \mathrm{m}\left(\xi_{4}\right.$ plate), which can be transferred to a change in the dimensionless number.

$$
\varphi^{\prime}=\mathrm{h}_{1} / \mathrm{Sq}
$$


Table 3. Experimental conditions.

\begin{tabular}{cc}
\hline Experiment Parameter & Conditions \\
\hline Fuel & $\mathrm{B} 15, \mathrm{~B} 25$ \\
Ambient temperature & $20^{\circ} \mathrm{C}$ \\
Ambient pressure & $0.1 \mathrm{MPa}$ \\
Injection pressure & $80 \mathrm{MPa}$ \\
impingement distance & $60 \mathrm{~mm}$ \\
Wall condition & Dry $/ \mathrm{FWW} / \mathrm{SWW}$ \\
\hline
\end{tabular}

\subsection{Adhered Film Characteristic Parameters}

\subsubsection{Adhered Fuel Mass Ratio}

After fuel impinging, some droplets will splash off the wall and some fuel will adhere to the plate, which affects the evaporation speed and mixture concentration distribution near the wall directly. In our previous study [30], we defined the adhering fuel ratio $(\varepsilon)$ on the dry wall condition as Equation (2).

$$
\varepsilon=\mathrm{m}_{\mathrm{ad}} / \mathrm{m}_{\mathrm{inj}},
$$

where the mass of the single injected fuel $\left(\mathrm{m}_{\mathrm{inj}}\right)$ and adhered fuel $\left(\mathrm{m}_{\mathrm{ad}}\right)$ were measured by using a precision balance $(0.01 \mathrm{mg})$. However, with the existence of the original lubricant film, the mass loss of lube oil $\left(\Delta \mathrm{m}_{1}\right)$ in the impingement process cannot be ignored. Therefore, under the wet wall conditions, Equation (2) can improved by the equation below.

$$
\varepsilon=\left(\mathrm{m}_{\mathrm{ad}}-\Delta \mathrm{m}_{\mathrm{l}}\right) / \mathrm{m}_{\mathrm{inj}} .
$$

\subsubsection{Longitudinal Section Profiles of Adhered Fuel Film}

A fusion deformation of liquid film in a short time after adhering will cause a distortion in measurement results. As shown in Figure 4, we make the longitudinal section profile in the middle of the film with 20 points of film thickness that represent the three-dimensional accumulation of adhered fuel film to show the integral film thickness distribution. The entire measurement length is $50 \mathrm{~mm}$ in the Y-axis direction (see Figure 1b).

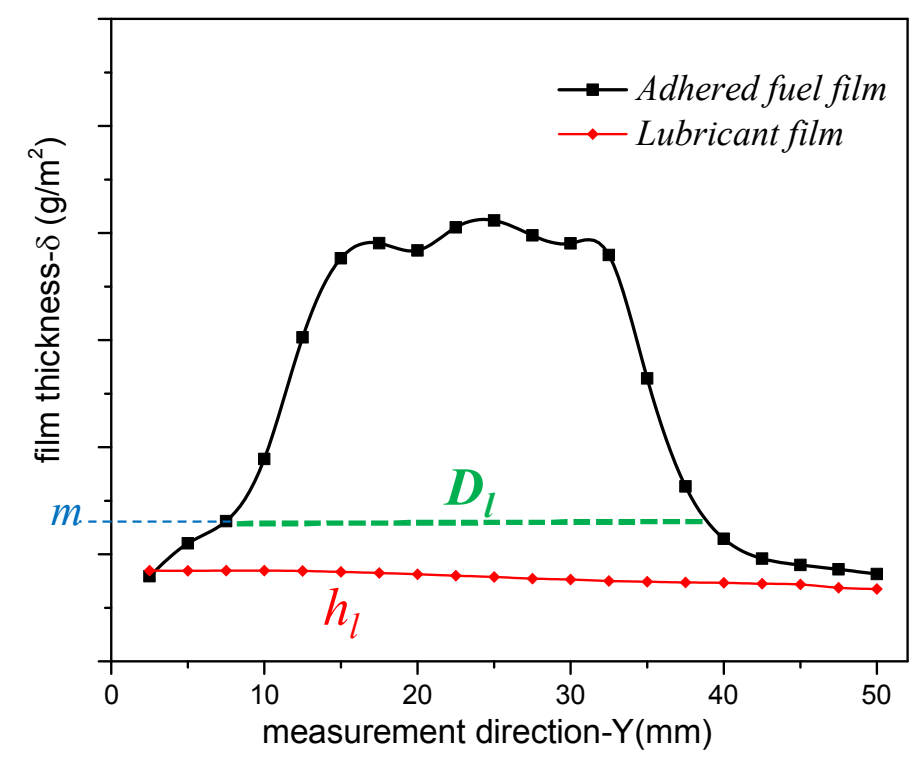

Figure 4. Thickness distribution of adhered fuel film represented by a longitudinal section profile in the middle of the film. 


\subsubsection{Average Thickness $\left(h_{a}\right)$ and Accumulated Diameter $\left(D_{1}\right)$ of Adhered Film}

As shown in Figure 4, the adhered fuel film accumulates around the impacting central point and presents a "mountain" shape. In Reference [31], it has made some similar definitions about thickness and diameter of adhered film, but it didn't consider the effect of the original lubricant film thickness. Therefore, we should re-define the metrical parameters. The red line is the original lubricant film with a mean thickness of $h_{1}\left(h_{1}=0\right.$ under dry wall conditions). To investigate the effect of roughness and wet walls on the evaporation and spreading of the adhered fuel film, we have defined two quantity factors to understand the adhered film, which include the average thickness $\left(h_{a}\right)$ and accumulated diameter $\left(D_{1}\right)$ as the formula below.

$$
\mathrm{h}_{\mathrm{a}}=\frac{1}{\mathrm{n}} \sum \mathrm{h}_{\mathrm{i}}, \mathrm{h}_{\mathrm{i}} \geq \mathrm{m}
$$

where $\mathrm{n}$ is the number of measured points, $\mathrm{h}_{\mathrm{i}}$ is the film thickness at each point, and $\mathrm{m}$ is a reference thickness $\left(\mathrm{g} / \mathrm{m}^{2}\right)$, which is the lower limit of the measurement points with a range of:

$$
\mathrm{m}=\left\{\begin{array}{l}
1.5, \mathrm{~h}_{1}=0 \\
3.0,1 \leq \mathrm{h}_{1} \leq 2 \\
4.0,2 \leq \mathrm{h}_{1} \leq 3 \\
5.0,3 \leq \mathrm{h}_{1} \leq 4
\end{array}\right.
$$

$D_{1}$ is a measured length of the line that is intercepted by the two sides of a film profile when the thickness is $\mathrm{m}$.

\section{Results and Discussion}

\subsection{Development of Adhering Fuel Mass Ratio}

Figure 5 shows the adhered fuel mass ratio $(\varepsilon)$ of the n-butanol/diesel blended fuels with $15 \%$ and $25 \%$ blending ratios at different roughness types for dry walls (a); FWW (b); and SWW (c). Regardless of whether the wall is dry or wet, the adhering ratio of B25 is higher than that of B15. This result may be consistent with Reference [32], which shows that higher n-butanol ratios imply a lower spreading radius and higher impinged spray heights interact with air. Due to the normal pressure and temperature, the masses for evaporation of the two blends that were sprayed before impinging were not significantly different. Due to the high injection pressure and the same injection pulse for the defined fuel-injected volume, the lower density of B25 implies a lower momentum for wall impact so that the rebounded mass will be less than that of B15. Combined with the decrease in viscosity and surface tension to lower the spreading resistance, an explanation can be provided for the phenomenon that, although trends for the two blended fuels are similar under dry wall or FWW conditions (Figure $5 \mathrm{a}, \mathrm{b}$ ), differences in $\varepsilon$ between these walls become insignificant for B25.

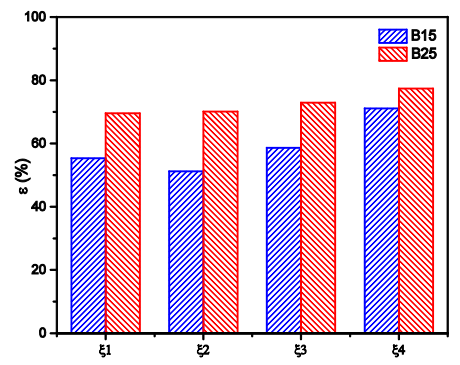

(a)

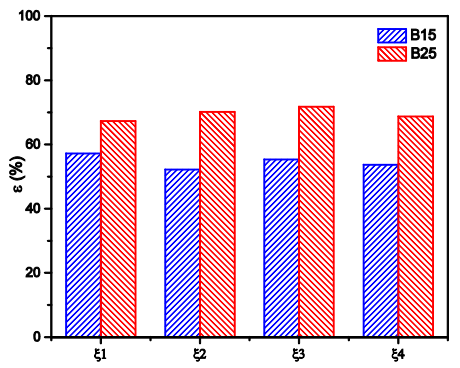

(b)

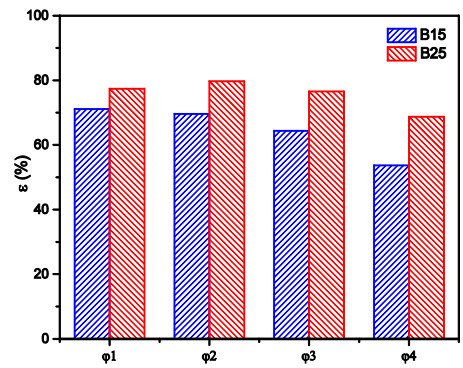

(c)

Figure 5. Adhering fuel mass ratio $(\varepsilon)$ of B15 and B25 with different wall conditions: (a) dry walls with different roughness; (b) FWW with different roughness; (c) SWW with different $\varphi^{\prime}$. 
The effect of roughness on $\varepsilon$ for B15 is relatively clear when the fuel impinges on dry walls. As shown in Figure 5a, the adhered fuel ratio presents an increasing trend with an increase in Sq and this trend can contribute to the reason for the liquid fuel drops impinging on the wall. The increase in roughness enhances liquid osmosis on the wall surface and hinders the evaporation of secondary smaller droplets. However, Figure $5 \mathrm{~b}$ shows that, when stripes on these walls are fully covered with lube oil, the adhered ratio remains almost unchanged, which means that, when the wall film is thicker than Sa or Sq, the influence of roughness on the droplet splash decreases or has no effect. A similar conclusion for a single water droplet impacting is provided in Reference [38].

After comparing the results of the dry wall and FWW conditions, it is important to research the regulation of $\varepsilon$ when the thickness of the original oil film is smaller than Sq. Figure $5 c$ shows the development in an adhered fuel ratio for B15 and B25 after spray impinges on the wall under SWW conditions. Since it is inconvenient to contrast the results between B15 and B25 from $\varphi^{\prime}$, which will change as $h_{1}$ changes in each procedure, a general term " $\varphi$ " was used in Figure $5 c$ to represent each lubricant film thickness. Additionally, $\varphi 1$ to $\varphi 4$ implies an increase in $\varphi^{\prime}$. Differences in the results are not obvious especially for higher n-butanol blends, but, in general, these exhibit a downward trend for $\varepsilon$ with an increase in $\varphi^{\prime}$. The presence of lubricant film increases the viscosity resistance for the fuel droplet splash so that the change in $\varepsilon$ can be small. Equation (3) shows that, with an injection pressure of $80 \mathrm{MPa}$, sprayed fuel has a large impact momentum and the lubricating film will bounce off the wall, increase the film quality difference $\Delta \mathrm{m}_{1}$, and decrease $\varepsilon$. Therefore, the findings of Figure $5 \mathrm{c}$ can be proof that, under similar engine conditions, a lower $\varepsilon$ does not imply an improvement in fuel and air mixture, but, rather, it means that more lube oil will be consumed and deteriorate the combustion.

\subsection{Adhered Fuel Film-Thickness Distribution}

\subsubsection{Dry Wall Conditions}

After fuel has impinged on the wall and splashed, the adhered liquid will gather and form a "mountain-like" film, which evaporates and mixes with environmental air to form combustible gas. At the same time, the distribution of fuel film influences the speed of evaporation. Figure 6 shows longitudinal section profiles of the adhered film for B15 and B25 blends with a change in roughness of the dry wall conditions. Most film peaks appear as a "W" shape, which means that a concave-ring exists around the central point of the impinged beam. Ring formation results because, after the liquid fuel impact on the wall, adhered fuel will accumulate at the impinging point and try to spread. Air has an entrainment effect on the spreading film edge, forms a resistance, and raises the edge. The liquid fuel surface tension makes the film edge rebound to the center at the same time. At this point, the B25 peak widths with a lower surface tension are larger than those of B15. Few differences exist among the height of these film peaks except on the $\xi_{2}$ wall. As described in Reference [39], this result implies that the impact of wall roughness on the impinging characteristic cannot be only required by average measured parameters such as Ra. In this work, we have found that the particularity of $\xi_{2}$ is that the skewness of the height distribution, Ssk, is lower than the other three plates and it means a higher convex extent is analyzed above. Therefore, with a fuel-droplet impact, the bounced mass will increase and the adhered film will be thinner. It also means that the roughness parameter Ssk of the surface has an important influence on the distribution of adhered film during the impingement process under a dry wall condition. 


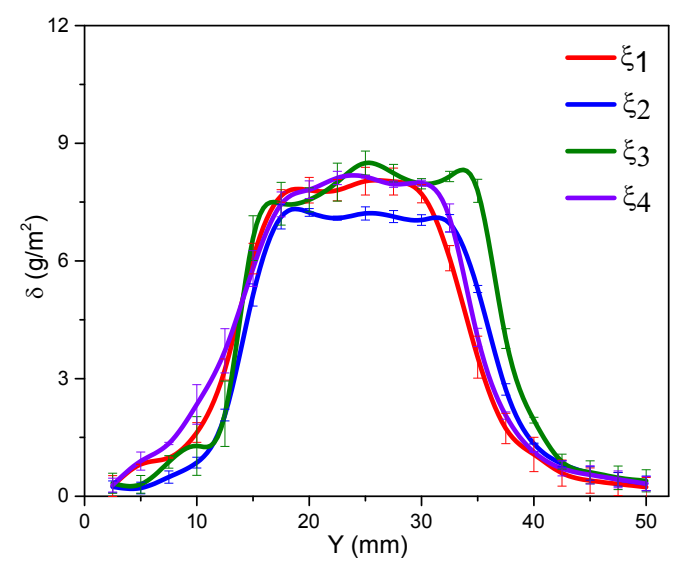

(a)

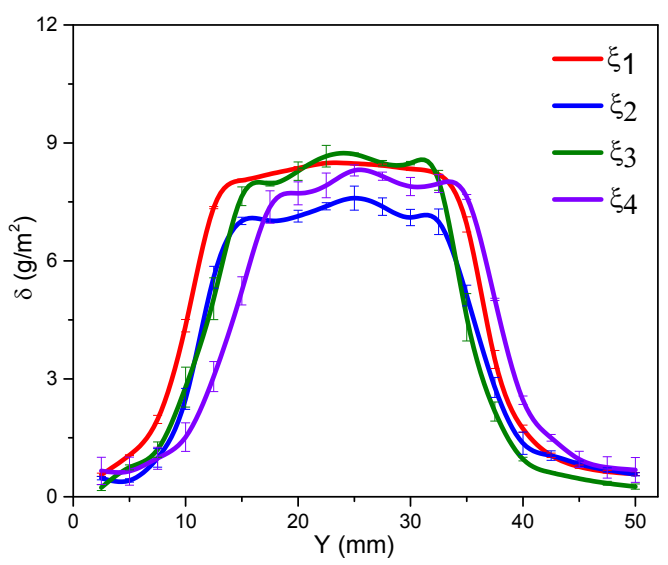

(b)

Figure 6. Longitudinal section profiles of adhered fuel film for (a) B15 and (b) B25 blends under dry wall conditions.

\subsubsection{FWW Conditions}

Figure 7 shows the longitudinal section profiles of the adhered fuel film for B15 and B25 blends with FWW conditions. The plates are covered by lubricating oil with a fixed thickness $\left(3-4 \mathrm{~g} / \mathrm{m}^{2}\right)$. The different dotted lines represent the original lube oil film thickness for each wall. Compared with the dry wall conditions, the concave-ring phenomenon still exists on FWW for the same reason as mentioned above. However, adhered peaks have a wider and flatter shape and the difference between these films is smaller. In combination with the analysis for the adhered fuel mass ratio, if the thickness of the original oil film is larger than the roughness parameter Sq, the lube oil's fusion effect plays a leading role in fuel spreading, which changes the peak shape rapidly and tends to spread over a larger area.

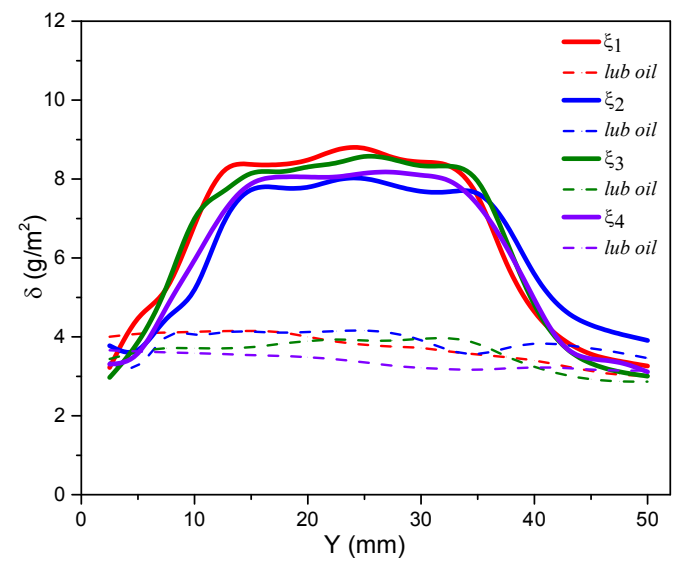

(a)

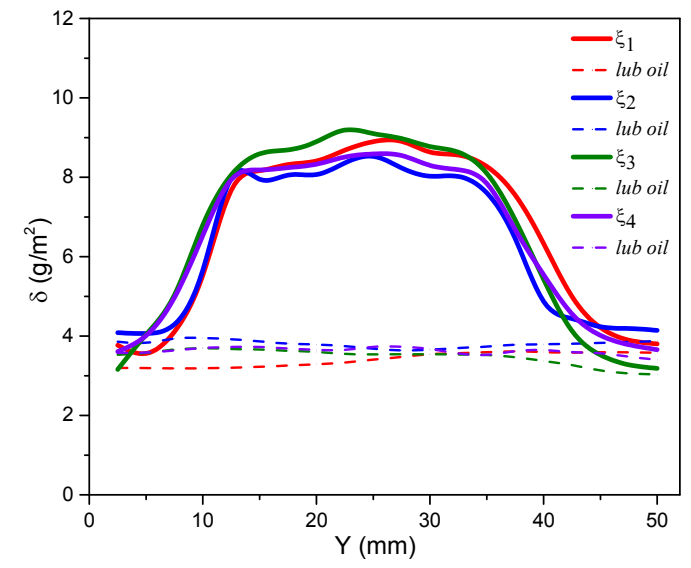

(b)

Figure 7. Longitudinal section profiles of adhered fuel film for (a) B15 and (b) B25 blends under FWW conditions.

\subsubsection{SWW Conditions}

Figure 8 shows the longitudinal section profiles (blue lines) of the blends after impinging on the $\xi_{4}$ wall with a change in original oil film thickness $\left(1-2 \mathrm{~g} / \mathrm{m}^{2}, 2-3 \mathrm{~g} / \mathrm{m}^{2}, 3-4 \mathrm{~g} / \mathrm{m}^{2}\right)$. The red lines include the lubricant film thickness before impact. The shape of the fuel film peaks with a $1-2 \mathrm{~g} / \mathrm{m}^{2}$ oil film thickness, which is almost the same as that on the dry wall. After the oil films change to $2-3 \mathrm{~g} / \mathrm{m}^{2}$ 
and $3-4 \mathrm{~g} / \mathrm{m}^{2}$, the shape of the adhered film peaks become smoother and flatter, which may indicate that when the original oil film is thicker than Sq by more than half, the fusion effect between the liquid fuel and the lubricating oil will be prominent and rapid. The effect of original lubricant film becomes larger than wall roughness. Therefore, it can be found that many automobile engine manufacturers use surface treatment to change the cylinder surface topography such as by using small pits to hold more oil for a better lubrication performance. However, in this situation, the oil film should be thick, which will yield a more fuel-lubricant mixture and results in an increased dilution and consumption of lube oil.

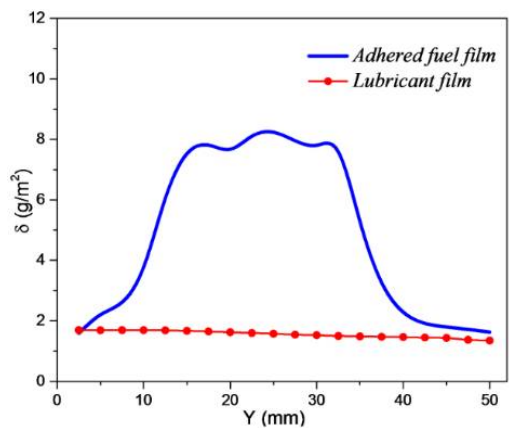

(a)

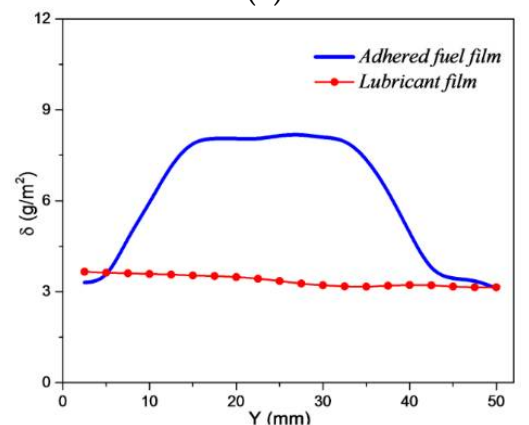

(c)

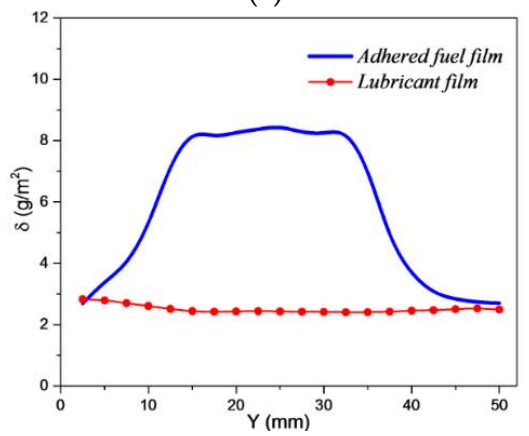

(e)

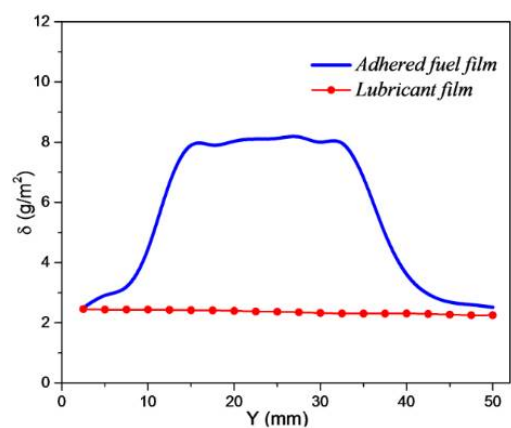

(b)

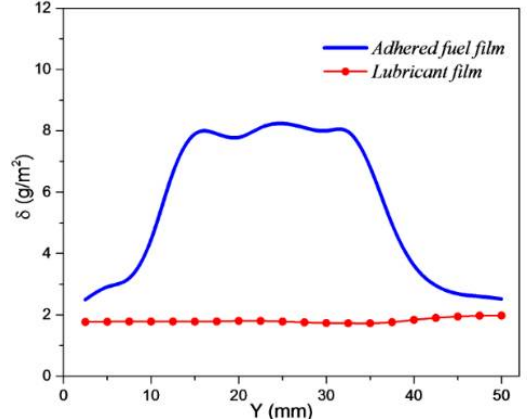

(d)

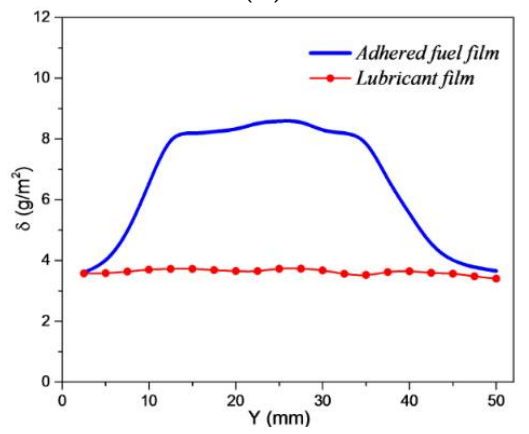

(f)

Figure 8. Longitudinal section profiles of adhered fuel film under SWW conditions: (a-c) B15 with different lubricant film thicknesses; (d-f) B25 with different lubricant film thicknesses.

\subsection{Average Thickness $\left(h_{a}\right)$ and Accumulated Diameter $\left(D_{l}\right)$}

Figure 9 shows the development of average thickness $\left(h_{a}\right)$ and accumulated diameter $\left(D_{1}\right)$ of the adhered film after spray impingement of B15 and B25 blends under three wall conditions. To provide reasonable contrast results, the weak impact of the density of lubricating oil is ignored and units of $h_{a}$ are converted from $\left(\mathrm{g} / \mathrm{m}^{2}\right)$ to $(\mu \mathrm{m})$. Under almost all conditions, $h_{a}$ and $D_{1}$ of $B 25$ are higher than those of B15 and the reason for this result can be added from the results of the adhering fuel ratio $\varepsilon$ for the lower rebounded mass of B25. Under dry wall conditions shown in Figure $9 a$, the variation in $D_{1}$ increases slowly with an increase in Sq. A larger Sq means a larger resistance for spreading adhered 
fuel, which causes more fuel to gather at the impact point. Due to the larger accumulated diameter with more adhered fuel mass, the change in $h_{a}$ with a different wall roughness is small, which implies that the roughness at this work scale is not the major factor that affects the adhered film's average thickness. Under FWW conditions, according to the above analysis, the influence of roughness is not clear after the lube oil has almost covered the wall surface texture. For SWW conditions, $h_{a}$ and $D_{1}$ mostly increase with a rise in $\varphi^{\prime}$. As the original lubricant film thickness increases, the fusion effect increases gradually and then promotes the spreading of adhered fuel away from the impingement point, which increases $D_{1}$. An increased $h_{1}$ improves the initial measured value $m$ in Equation (4), increases the average film thickness $h_{a}$, and emphasizes the important influence of splashing lube oil mass $\Delta \mathrm{m}_{1}$ on the decrease in $\varepsilon$, which is shown in Figure $5 \mathrm{c}$.

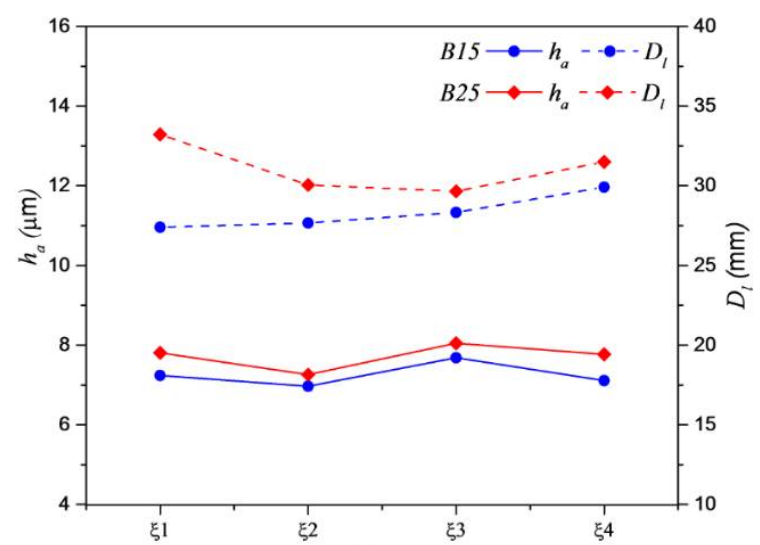

(a)

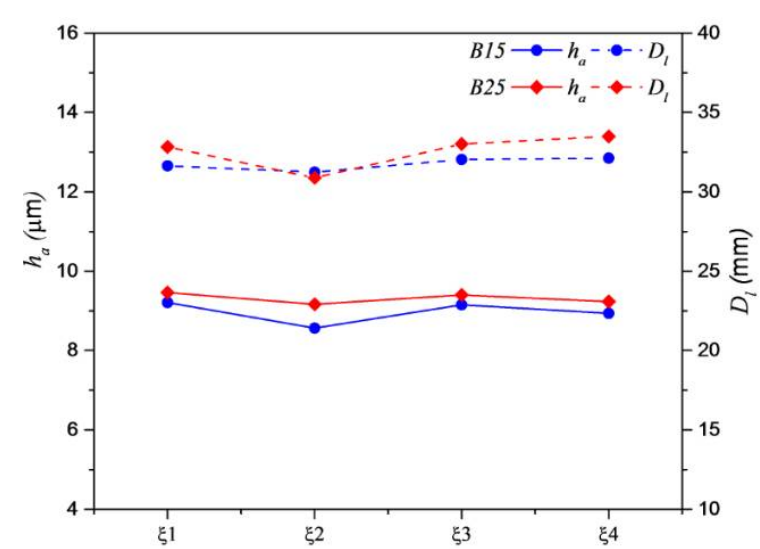

(b)

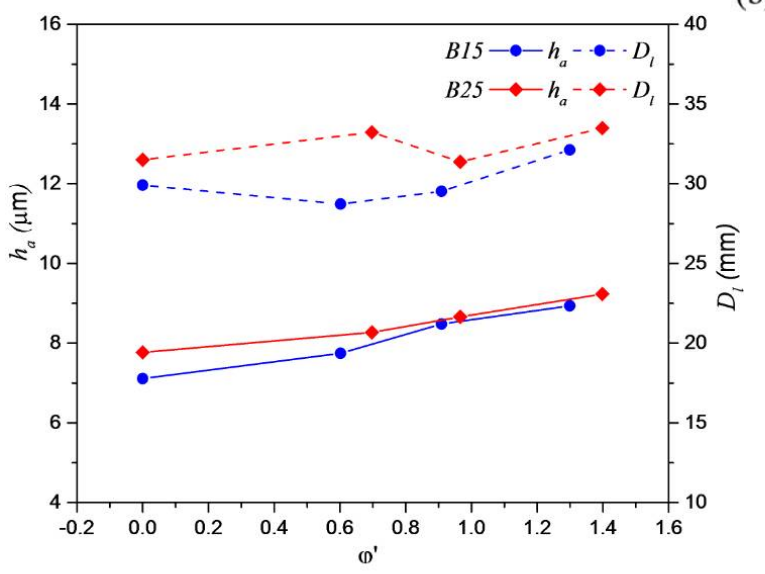

(c)

Figure 9. Mean thickness $h_{a}$ and accumulated diameter $D_{1}$ of adhered fuel film with different wall conditions: (a) dry walls with different roughness; (b) FWW with different roughness; (c) SWW with different $\varphi^{\prime}$.

\section{Conclusions}

An experimental study was conducted to investigate the effect of surface roughness and lubricant film on the characteristics of the adhered fuel film of n-butanol-diesel blending fuels after spray impingement. The lubricant film thickness can be changed. We mainly focus on the development of the adhered mass ratio, the thickness distribution, and the morphological characteristics of the adhered fuel film. The main conclusions are below.

(1) The adhered fuel film mass ratio $\varepsilon$ of B25 is larger than B15 for a lower splashing mass of B25 that is caused by the smaller impinged momentum. However, gaps of $\varepsilon$ between different surface roughness types became inconspicuous with an increase in n-butanol blending ratio. $\varepsilon$ increases 
with a rise in roughness Sq under dry wall conditions, but decreases with an increase in lube oil film thickness under FWW conditions.

(2) The thickness distribution of the adhered fuel film does not change much with different $\mathrm{Sa}$ or $\mathrm{Sq}$, but the film profile of the $\xi_{2}$ wall showed a lower shape than others, which signifies that Sa or Sq were not the only parameters that were used to evaluate the effect of roughness. This plate has a lower Ssk, which determined the overall concave-convex degree of the wall. The influence of roughness was insignificant for a lubricant film thickness that was greater than Sq.

(3) The mean thickness $h_{a}$ and accumulated diameter $D_{1}$ of B25 were higher than those of B15 under almost all conditions and stable developments of $h_{a}$ and $D_{1}$ resulted in dry walls and FWW. Both were enhanced by an increase in $\varphi^{\prime}$, which implies that, under thinner lubricant film conditions $\left(\varphi^{\prime}<1\right)$, the wall roughness is an important factor that cannot be ignored for an impacting process.

Author Contributions: X.L., H.Z., and H.Y. designed and performed the experiments. H.Z. and Y.W. analyzed the data and discussed the results and implications. G.S. and X.L. provided the research direction. X.L. and H.Z. wrote the paper. X.S. and M.G. helped edit the paper.

Funding: This research was funded by National Natural Science Foundation of China [91641111] and National Sci-Tech Support of China [2016YFC0205304].

Acknowledgments: The authors want to mention the support of the Marine Low-Speed Engine Project (Phase I) of MIIT.

Conflicts of Interest: The authors declare no conflict of interest.

\section{Abbreviations}

$\mathrm{Sq} \quad$ surface roughness parameter-root mean square height $(\mu \mathrm{m})$

$\mathrm{h}_{1} \quad$ mean thickness of original lubricant film $\left(\mathrm{g} / \mathrm{m}^{2}\right)$

SWW semi-wetted walls

FWW fully wetted walls

B15/B25 15\%/25\% volumetric blended ratio of n-butanol in blending fuels

$\varepsilon \quad$ adhering fuel mass ratio (\%)

Ssk surface roughness parameter-skewness

$\mathrm{h}_{\mathrm{a}} \quad$ mean thickness of adhered fuel film $(\mu \mathrm{m})$

$\mathrm{D}_{\mathrm{l}} \quad$ accumulated diameter of adhered fuel film (mm)

$\mathrm{Ra} \quad$ one-dimensional surface roughness parameter-Arithmetic mean height $(\mu \mathrm{m})$

$\mathrm{Rq} \quad$ root mean square deviation of a line $(\mu \mathrm{m})$

$\mathrm{Sa} \quad$ two-dimensional surface roughness parameter-Arithmetic mean height $(\mu \mathrm{m})$

$\xi_{1}-\xi_{4} \quad$ four walls with increasing surface roughness Sq

A area of the measured region for surface roughness

$\varphi^{\prime} \quad \varphi^{\prime}=\mathrm{h}_{1} / \mathrm{Sq}$

$\Delta \mathrm{m}_{\mathrm{l}} \quad$ the mass loss of lube oil in the impingement process (mg)

$\mathrm{Y}$ the measurement direction of the adhered fuel film thickness ( $\mathrm{mm}$ )

$\delta \quad$ liquid film thickness $\left(\mathrm{g} / \mathrm{m}^{2}\right)$

$\varphi \quad$ conditions with different original lubricant film thicknesses

\section{References}

1. Yao, M.; Zheng, Z.; Liu, H. Progress and recent trends in homogeneous charge compression ignition (HCCI) engines. Prog. Energy Combust. Sci. 2009, 35, 398-437. [CrossRef]

2. Coskun, G.; Soyhan, H.S.; Demir, U.; Turkcan, A.; Ozsezen, A.N.; Canakci, M. Influences of second injection variations on combustion and emissions of an HCCI-DI engine: Experiments and CFD modelling. Fuel 2014, 136, 287-294. [CrossRef]

3. D'Ambrosio, S.; Ferrari, A. Effects of exhaust gas recirculation in diesel engines featuring late PCCI type combustion strategies. Energy Convers. Manag. 2015, 105, 1269-1280. [CrossRef] 
4. Kiplimo, R.; Tomita, E.; Kawahara, N.; Yokobe, S. Effects of spray impingement, injection parameters, and EGR on the combustion and emission characteristics of a PCCI diesel engine. Appl. Therm. Eng. 2012, 37, 165-175. [CrossRef]

5. Kook, S.; Park, S.; Bae, C. Influence of early fuel injection timings on premixing and combustion in a diesel engine. Energy Fuels 2007, 22, 331-337. [CrossRef]

6. Akop, M.; Zama, Y.; Furuhata, T.; Arai, M. Characteristics of adhesion of diesel fuel on impingement disk wall. Part 1: Effect of impingement area and inclination angle of disk. At. Sprays 2013, 23, 725-744. [CrossRef]

7. Akop, M.; Zama, Y.; Furuhata, T.; Arai, M. Characteristics of adhesion diesel fuel on an impingement disk wall. Part 3: Ambient pressure effect. At. Sprays 2014, 24, 625-650. [CrossRef]

8. Oliveira Panão, M.R.; Moreira, A.L.N.; Durão, D.F.G. Effect of a cross-flow on spray impingement with port fuel injection systems for HCCI engines. Fuel 2013, 106, 249-257. [CrossRef]

9. Wang, Z.; Guo, H.; Wang, C.; Xu, H.; Li, Y. Microscopic level study on the spray impingement process and characteristics. Appl. Energy 2017, 197, 114-123. [CrossRef]

10. Zhang, Z.; Chi, Y.; Shang, L.; Zhang, P.; Zhao, Z. On the role of droplet bouncing in modeling impinging sprays under elevated pressures. Int. J. Heat Mass Transf. 2016, 102, 657-668. [CrossRef]

11. Estrade, J.; Carentz, H.; Lavergne, G.; Biscos, Y. Experimental investigation of dynamic binary collision of ethanol droplets-a model for droplet coalescence and bouncing. Int. J. Heat Fluid Flow 1999, 20, 486-491. [CrossRef]

12. Moreira, A.L.N.; Moita, A.S.; Panão, M.R. Advances and challenges in explaining fuel spray impingement: How much of single droplet impact research is useful? Prog. Energy Combust. Sci. 2010, 36, 554-580. [CrossRef]

13. Deendarlianto; Takata, Y.; Kohno, M.; Hidaka, S.; Wakui, T.; Majid, A.I.; Kuntoro, H.Y.; Indarto; Widyaparaga, A. The effects of the surface roughness on the dynamic behavior of the successive micrometric droplets impacting onto inclined hot surfaces. Int. J. Heat Mass Transf. 2016, 101, 1217-1226. [CrossRef]

14. Tang, C.; Qin, M.; Weng, X.; Zhang, X.; Zhang, P.; Li, J.; Huang, Z. Dynamics of droplet impact on solid surface with different roughness. Int. J. Multiph. Flow 2017, 96, 56-69. [CrossRef]

15. Zhang, Z.; Liu, H.; Zhang, F.; Yao, M. Numerical study of spray micro-droplet impinging on dry/wet wall. Appl. Therm. Eng. 2016, 95, 1-9. [CrossRef]

16. Guo, Y.; Wei, L.; Liang, G.; Shen, S. Simulation of droplet impact on liquid film with CLSVOF. Int. Commun. Heat Mass Transf. 2014, 53, 26-33. [CrossRef]

17. Lee, C.S.; Choi, N.J. Effect of air injection on the characteristics of transient response in a turbocharged diesel engine. Int. J. Therm. Sci. 2002, 41, 63-71. [CrossRef]

18. Imdadul, H.K.; Masjuki, H.H.; Kalam, M.A.; Zulkifli, N.W.M.; Alabdulkarem, A.; Rashed, M.M.; Teoh, Y.H.; How, H.G. Higher alcohol-biodiesel-diesel blends: An approach for improving the performance, emission, and combustion of a light-duty diesel engine. Energy Convers. Manag. 2016, 111, 174-185. [CrossRef]

19. Rakopoulos, D.C.; Rakopoulos, C.D.; Giakoumis, E.G.; Dimaratos, A.M.; Kyritsis, D.C. Effects of butanol-diesel fuel blends on the performance and emissions of a high-speed DI diesel engine. Energy Convers. Manag. 2010, 51, 1989-1997. [CrossRef]

20. Polat, S. An experimental study on combustion, engine performance and exhaust emissions in a HCCI engine fuelled with diethyl ether-ethanol fuel blends. Fuel Process. Technol. 2016, 143, 140-150. [CrossRef]

21. Ge, J.; Yoon, S.; Choi, N. Using Canola Oil Biodiesel as an Alternative Fuel in Diesel Engines: A Review. Appl. Sci. 2017, 7, 881. [CrossRef]

22. Lapuerta, M.; Armas, O.; Rodriguezfernandez, J. Effect of biodiesel fuels on diesel engine emissions. Prog. Energy Combust. Sci. 2008, 34, 198-223. [CrossRef]

23. Huang, H.; Liu, Q.; Yang, R.; Zhu, T.; Zhao, R.; Wang, Y. Investigation on the effects of pilot injection on low temperature combustion in high-speed diesel engine fueled with $\mathrm{n}$-butanol-diesel blends. Energy Convers. Manag. 2015, 106, 748-758. [CrossRef]

24. Doğan, O. The influence of n-butanol/diesel fuel blends utilization on a small diesel engine performance and emissions. Fuel 2011, 90, 2467-2472. [CrossRef]

25. Mo, J.; Tang, C.; Li, J.; Guan, L.; Huang, Z. Experimental investigation on the effect of n-butanol blending on spray characteristics of soybean biodiesel in a common-rail fuel injection system. Fuel 2016, 182, 391-401. [CrossRef] 
26. Chen, Z.; Liu, J.; Han, Z.; Du, B.; Liu, Y.; Lee, C. Study on performance and emissions of a passenger-car diesel engine fueled with butanol-diesel blends. Energy 2013, 55, 638-646. [CrossRef]

27. Yao, M.; Wang, H.; Zheng, Z.; Yue, Y. Experimental study of n-butanol additive and multi-injection on HD diesel engine performance and emissions. Fuel 2010, 89, 2191-2201. [CrossRef]

28. Şahin, Z.; Aksu, O.N. Experimental investigation of the effects of using low ratio n-butanol/diesel fuel blends on engine performance and exhaust emissions in a turbocharged DI diesel engine. Renew. Energy 2015, 77, 279-290. [CrossRef]

29. Yilmaz, N.; Vigil, F.M.; Benalil, K.; Davis, S.M.; Calva, A. Effect of biodiesel-butanol fuel blends on emissions and performance characteristics of a diesel engine. Fuel 2014, 135, 46-50. [CrossRef]

30. Yu, H.; Liang, X.; Shu, G.; Sun, X.; Zhang, H. Experimental investigation on wall film ratio of diesel, butanol/diesel, DME/diesel and gasoline/diesel blended fuels during the spray wall impingement process. Fuel Process. Technol. 2017, 156, 9-18. [CrossRef]

31. Yu, H.; Liang, X.; Shu, G.; Wang, X.; Wang, Y.; Zhang, H. Experimental Investigation on Wall Film Distribution of Dimethyl Ether/Diesel Blended Fuels Formed during Spray Wall Impingement. Energies 2016, 9, 949. [CrossRef]

32. Yu, H.; Liang, X.; Shu, G.; Wang, Y.; Zhang, H. Experimental investigation on spray-wall impingement characteristics of n-butanol/diesel blended fuels. Fuel 2016, 182, 248-258. [CrossRef]

33. Thongcha., S.; Chollacoop, N.; Topaiboul, S.; Suwannakij, K.; Charoenphonphanich, C.; Hanamura, K. Feasibility Study of Using High Butanol-Diesel Blends in Commonrail Engine. In Proceedings of the 23rd Conference of the Mechanical Engineering Network of Thailand, Chiang Mai, Thailand, 4-7 November 2009.

34. Tong, J. Thermal Physical Properties of the Fluid: Basic Principle and Calculation; China Petrochemical Press: Beijing, China, 2008.

35. Zhang, H.; Liang, X.; Yu, H.; Wang, Y.; Weijian, C. Experimental Study on the Adhering Fuel Film of the Impinged N-Butanol-Diesel Blends. In Proceedings of the ASME 2016 International Mechanical Engineering Congress and Exposition, Phoenix, AZ, USA, 11-17 November 2016.

36. Fuwa, K.; Valle, B. The Physical Basis of Analytical Atomic Absorption Spectrometry. The Pertinence of the Beer-Lambert Law. Anal. Chem. 1963, 35, 942-946. [CrossRef]

37. Introduction to Roughness-Parameters of Surface Roughness. Available online: https://www.keyence.com/ ss/products / microscope/roughness/surface/sq-root-mean-square-height.jsp (accessed on 5 June 2018).

38. Liang, G.; Mudawar, I. Review of mass and momentum interactions during drop impact on a liquid film. Int. J. Heat Mass Transf. 2016, 101, 577-599. [CrossRef]

39. Kalantari, D.; Tropea, C. Spray impact onto flat and rigid walls: Empirical characterization and modelling. Int. J. Multiph. Flow 2007, 33, 525-544. [CrossRef] 